\title{
ANÁlise REFleXiVA dA PRÁtica PROFISSIONAL BIOMÉdica NO CAMPO DO ESTÁGIO SUPERVISIONADO
}

\author{
REFLECTIVE ANALYSIS OF PROFESSIONAL BIOMEDICAL PRACTICE IN THE SUPERVISED \\ INTERNSHIP FIELD
}

ANÁLISIS REFLEXIVO DE LA PRÁCTICA BIOMÉDICA PROFESIONAL EN EL CAMPO DE PRÁCTICAS SUPERVISADAS

\section{Letícia Cristina Gonçalves \\ (iD) 9 \\ Mestrado em Biologia Celular e \\ Molecular (UNESP-RC) \\ Supervisora de estágio na FHO- \\ Uniararas \\ Discente no programa de Pós \\ Graduação em Ciências Biológicas \\ lcgoncalvess@gmail.com}

\section{Samuel de Souza Neto (iD) 9}

Livre-Docência (UNESP)

Professor Associado na

Universidade Paulista Júlio de

Mesquita Filho- (UNESP)

samuel.souza-neto@unesp.br

\begin{abstract}
Resumo
Este trabalho objetiva identificar e analisar os saberes mobilizados na prática de uma supervisora de estágio obrigatório do curso de Biomedicina de instituição privada do interior paulista. Para isto, optou-se pelo estudo descritivo exploratório e analítico, com uma abordagem qualitativa que envolveu como técnica o relato das rotinas. A análise dos saberes mobilizados na prática foi fundamentada nas quatro ações da reflexão crítica: descrição, informação, confrontação e reconstrução. Entre os resultados, observou-se a pluralidade dos saberes que ocorrem simultaneamente e orientam a prática docente. Consequentemente, verificou-se um modelo emergente de formação dado pela tríade: reflexão, pesquisa e crítica. Como desafio, emerge que a área do estágio necessita da inclusão da integralidade e humanização para romper com os limites da formação fragmentada. Concluindo, a análise de práticas deve ser considerada não só um dispositivo que permita identificar a mobilização de saberes, mas também de construção de uma epistemologia da prática profissional.
\end{abstract}

Palavras-chave: Estágio Supervisionado. Análise de Práticas. Saberes Docentes. Biomedicina. Dispositivo.

Recebido em: 12 de julho de 2021.

Aprovado em: 14 de deembro de 2021.

Como citar esse artigo (ABNT):

GONÇALVES, Letícia Cristina; SOUZA NETO, Samuel de. Análise reflexiva da prática profissional biomédica no campo do estágio supervisionado. Revista Prática Docente, v. 6, n. 3, e097, 2021.

http://doi.org/10.23926/RPD.2021.v6.n3.e097.id1269 


\section{Abstract}

This work aims to identify and analyze the knowledge mobilized in the practice of a mandatory internship supervisor of the Biomedicine course at a private institution in the interior of São Paulo. For this, we opted for the exploratory and analytical descriptive study, with a qualitative approach that involves the reporting of routines as a technique. An analysis of the knowledge mobilized in practice was based on the four actions of critical reflection: description, information, confrontation and reconstruction. Among the results, it was observed that the plurality of knowledge that occurs simultaneously and guides teaching practice. Consequently, there was an emerging model of training given by the triad: reflection, research and criticism. As the challenge, it emerges that an area of the internship needs the inclusion of integrality and humanization to break the limits of fragmented formation. In conclusion, an analysis of practices must be considered not only a device that allows the identification of a mobilization of knowledge, but also the construction of an epistemology of professional practice.

Keywords: Supervised Internship. Analysis of Practices. Teaching Knowledge. Biomedicine. Device.

\section{Resumen}

Este trabajo tiene como objetivo identificar y analizar los conocimientos movilizados en la práctica de un supervisor de pasantía obligatorio del curso de Biomedicina de una institución privada en el interior de São Paulo. Para ello, optamos por un estudio descriptivo exploratorio y analítico, con enfoque cualitativo que involucró el reporte de rutinas como técnica. El análisis del conocimiento movilizado en la práctica se basó en las cuatro acciones de reflexión crítica: descripción, información, confrontación y reconstrucción. Entre los resultados, hubo una pluralidad de conocimientos que se dan de manera simultánea y orientan la práctica docente. Consecuentemente, surgió un modelo de formación impartido por la tríada: reflexión, investigación y crítica. Como desafío, surge que el área de prácticas necesita la inclusión de la integralidad y la humanización para romper los límites de la formación fragmentada. En conclusión, el análisis de prácticas debe ser considerado no solo un dispositivo que permita la identificación de la movilización del conocimiento, sino también la construcción de una epistemología de la práctica profesional.

Palabras clave: Pasantía supervisada. Análisis de prácticas. Enseñanza del conocimiento. Biomedicina. Dispositivo. 


\section{INTRODUÇÃO}

Este trabalho trata dos saberes mobilizados na prática de uma supervisora de estágio obrigatório do curso de Biomedicina de instituição privada do interior paulista. No campo da Biomedicina, a formação do biomédico é feita em curso superior, na qual o estágio se configura como uma etapa decisiva da prática profissional, uma vez que este profissional se especializa em análises clínicas, exigindo uma expertise no trabalho de laboratório.

Assim, a instituição de formação compromete-se, em seu próprio Laboratório de Análises Clínicas, a oferecer o estágio curricular supervisionado (ECS) na área de "Análises Clínicas", buscando uma articulação entre os conhecimentos técnico-científicos. Portanto, o ECS em Análises Clínicas tem como finalidade o exercício prático e o aprimoramento dos conhecimentos técnico-científicos, visando a execução e interpretação dos exames que compõem a prática laboratorial: imunologia, hematologia, microbiologia, bioquímica, parasitologia, urinálise e lavagem/esterilização, a fim de habilitá-los em patologia clínica. Neste contexto, cada supervisor de estágio trabalha com um grupo de 5 a 8 estudantes na orientação e acompanhamento dessa prática profissional.

Neste percurso formativo, a graduação na área de saúde permite ao indivíduo atuar na profissão em que se especializou (TARDIF, 2000). Entretanto, não necessariamente o capacita para ensinar essa profissão, pois os professores universitários em saúde, especialistas na sua área, apresentam carências tanto na formação pedagógica quanto técnica e filosófica (TREVISO; ERCÍLIA; DA COSTA, 2017). Porém, Neto, Cyrino e Borges (2019) apontam que o educador deve conhecer os elementos do saber profissional docente, para que haja uma melhora na qualidade e competência profissionais.

Neste contexto, o docente deve construir uma identidade profissional também no âmbito da docência, para definir habilidades, saberes e atividades envolvidas no exercício da docência, na prática docente. Dessa forma, torna-se imprescindível trabalhar a formação dos novos biomédicos nos contextos em que eles são convidados a serem protagonistas de novas práticas. Entretanto, há uma dicotomia entre a formação mais técnico-científica e a formação reflexiva: a primeira gera profissionais mais técnicos e despreparados para situações complexas e singulares do ensino-aprendizagem; mas a outra reflete a perspectiva da prática como lócus de formação e produção de saberes, envolvendo a base de conhecimentos do professor (PENTEADO; SOUZA NETO, 2021; RUFINO; SOUZA NETO, 2021; TARDIF, 2000; HOLMES GROUP, 1986) e as dimensões reflexivas: conhecimento na ação, reflexão na ação 
e reflexão sobre a ação (SOUZA NETO; BORGES; AYOUB, 2021; ALTARUGIO; SOUZA NETO, 2019; ORTIZ, 2003).

No âmbito desse processo, a mobilização desses conhecimentos/saberes em situação de prática profissional pode dar origem a uma epistemologia da prática profissional, envolvendo, ainda, uma perspectiva "ecológica" composta pelo estudo das diferentes atividades desenvolvidas pelos professores (TARDIF, 2000). A prática docente ganha destaque devido ao reconhecimento da sua relevância como lócus de mobilização, construção e ressignificação de saberes (TARDIF; LESSARD, 2011), dando fecundidade à análise das práticas como ferramenta estratégica da racionalidade da prática (SCHÖN, 1983) e apontando para a questão norteadora desse trabalho: como ocorre a mobilização dos saberes durante a prática profissional de uma supervisora de estágio acadêmico obrigatório em análises clínicas no curso de Biomedicina?

\subsection{OBJETIVOS}

Como objetivos, buscou-se identificar e analisar os saberes mobilizados por uma orientadora de estágio supervisionado ${ }^{1}$ por meio da análise da prática profissional. Trata-se de uma reflexão que envolve aspectos da docência na formação de futuros biomédicos, dos saberes envolvidos nas rotinas que abarcam protocolos e de técnicas específicas do campo da saúde.

\subsection{REFERENCIAL TEÓRICO}

O conceito epistêmico "saber" imprime-se por meio de um novo enfoque históricoepistemológico, o qual considera a complexidade do dever docente. Dessa forma, o saber é considerado um produto da operação de tratamento do conhecimento que rompe com velhos paradigmas, uma vez que há o reconhecimento da construção e reconstrução dos diferentes saberes dos professores durante a interação discente, docente e até mesmo com outras culturas no ambiente escolar (SOUZA NETO; BORGES, 2016).

Dessa forma, as discussões sobre saberes docentes e formação de professores ganharam impulso na literatura educacional desde o final do século XX, emergindo com o objetivo de revelar os saberes implícitos e explícitos na prática docente. Consequentemente, inúmeras

\footnotetext{
${ }^{1} \mathrm{Na}$ Lei 11788/2008, o professor da universidade que trabalha com o estágio profissional obrigatório (estágio curricular supervisionado) e o acompanha é denominado de orientador; enquanto o professor de escola que acompanha o estagiário é denominado de supervisor. Na literatura internacional, o professor da universidade que orienta e acompanha o ECS é denominado de supervisor (CYRINO; SOUZA NETO, 2014). Porém, no curso de Biomedicina da instituição elucidada, ele acontece na própria universidade, sendo denominado de laboratório escola. Dessa forma, este professor desempenha a dupla função de ser orientador e supervisor.
} 
pesquisas têm se desenvolvido com o propósito de investigar a formação dos professores em relação aos saberes mobilizados durante a prática profissional (SOUZA NETO; CYRINO; BORGES, 2019; SOUZA NETO; SARTI; CYRINO, 2018; TARDIF; LESSARD, 2011; GAUTHIER et al., 1998), culminando em uma variedade de tipologias e classificações dos saberes. No Brasil, os saberes foram inicialmente investigados por Tardif e Lessard (2011) e, posteriormente, por Gauthier et al. (1998), assim como por Souza Neto, Sarti e Cyrino (2018), entre outros.

Tardif (2000) apresenta o saber dos professores por meio de seis fios condutores. O primeiro fio é o saber e trabalho, o qual compreende uma íntima relação entre o saber do professor com o trabalho prático, cujos princípios permitem enfrentar e solucionar situações cotidianas. O segundo fio condutor, a diversidade do saber, classifica os saberes dos professores como plurais e heterogêneos. O terceiro, denominado temporalidade do saber, sugere a história de vida e uma carreira profissional como forma de aquisição para o saber. O quarto fio, a experiência de trabalho enquanto fundamento do saber, considera os saberes oriundos da experiência do trabalho cotidiano como alicerce da prática e da competência profissional. $\mathrm{O}$ quinto, saberes humanos a respeito de saberes humanos, propõe a ideia de um trabalho interativo baseada na relação humana entre o profissional e seu objeto de trabalho. O sexto e o último, saberes e formação profissional, demonstra a necessidade de refletir sobre a formação para a docência, considerando os saberes dos professores e as realidades específicas do trabalho educacional em seu cotidiano.

Outros autores, como Gauthier et al (1998), realizaram estudos acerca do ensino, identificando as implicações e formulando problemáticas, pelos quais obtiveram resultados relevantes que possibilitaram o desenvolvimento de uma teoria geral da pedagogia baseada na relação dos saberes mobilizados na prática pedagógica. Com o avanço da pesquisa, o autor e pesquisadores identificaram dois obstáculos que historicamente se interpuseram à pedagogia: ofício sem saberes e saberes sem ofício.

O primeiro obstáculo, ofício sem saberes, se refere à própria atividade docente que é exercida sem revelar os saberes inerentes que compõem essa prática (SOUZA NETO; CYRINO; BORGES, 2019). Ou seja, apesar de o ensino ser uma atividade que se realiza desde a antiguidade, ainda há pouco conhecimento acerca deste e, consequentemente, certas ideias preconcebidas contribuem diretamente para o "erro de manter o ensino na cegueira conceitual" (GAUTHIER, 1998). 
O segundo obstáculo, saberes sem ofício, se refere aos conhecimentos produzidos nos centros acadêmicos. De acordo com o autor, esses saberes não consideram as condições concretas do magistério, no qual o professor real enfrenta muitas variáveis que interferem diretamente no processo de ensino, exigindo tomadas de decisões. Assim, o desafio da profissionalização docente é transpor esses obstáculos - o ofício sem saberes e os saberes sem ofício -, objetivando um ofício feito de saberes (GAUTHIER, 1998).

O ofício de saberes surge perante a existência de um repertório de conhecimentos próprios do ensino. Para isso, o autor classifica os saberes como: saberes da tradição pedagógica, saberes disciplinares, saberes da ciência da educação, saberes curriculares, saberes experimentais e saberes da ação pedagógica. Os últimos, os saberes da ação pedagógica, podem ser considerados como o resultado da relação de complementação estabelecida entre os demais saberes do professor, os quais direcionam a decisão da ação a ser tomada, de acordo com cada caso específico ocorrido em sala de aula. Ou seja, o saber da ação pedagógica é o saber experiencial a partir do momento em que se torna público, sendo testado e validado (GAUTHIER, 1998).

Em geral, do ponto de vista tipológico, os autores descritos acima apresentam classificações diferentes, entretanto, não são tão singulares a ponto de serem excludentes, uma vez que todos se dedicam a investigar a mobilização dos saberes nas ações dos professores. As peculiaridades estão localizadas nos interesses investigativos, por exemplo, Gauthier et al. (1998) consideram um "ofício feito de saberes" baseado numa teoria geral da pedagogia, enquanto Tardif (2000) apresenta a epistemologia da prática profissional dos professores com ênfase no trabalho docente.

Neste contexto, a formação profissional mudou, pois não bastava mais só ter as noções básicas para ensinar ou levar o discente a aprender. Consequentemente, o currículo ganhou relevância juntamente com a epistemologia da prática (SCHON, 1992), no âmbito de um currículo pautado em uma racionalidade prática.

Dessa forma, a produção dos saberes foi compreendida como fonte subsidiária da ação prática, que se reelabora e se reestrutura a partir da mesma. Ou seja, durante a prática educativa, os saberes docentes são aplicados, testados, verificados e desta forma vão sendo legitimados, caracterizando uma dinâmica pela qual os saberes também se originam. Consequentemente, a prática ganhou maior destaque e tornou-se o objeto de pesquisa (SILVA, 2014).

Gatti (2014) concebe a prática como o lugar de: 
relações profissionais de ensino no qual surgem conhecimentos vitais sobre os processos do exercício da docência com crianças e jovens, é o lugar em que a criatividade docente emerge, é o momento onde não apenas nos defrontamos com uma reprodução estéril, mas com soluções criativas e novas compreensões sobre a relação didática (GATTI, 2014, p. 18).

Assim, de modo geral, essa base de conhecimento forma-se a partir das vivências e análises de práticas concretas que permitem um diálogo entre a prática profissional (experiências adquiridas em salas de aula) e a formação teórica. Pérez Gómez (1995) sugere três dimensões para se conceber a prática pedagógica: a primeira relaciona-se à atividade técnica baseada na racionalidade técnica como resultado "prático" da exposição de uma teoria; a segunda é a dimensão heurística, caracterizada como a valorização do subjetivo, no qual se estimulam os valores e se orienta a intencionalidade educativa; por fim, a terceira é a dimensão ética, que abrange a dualidade entre a qualidade do ensino e as estratégias utilizadas.

No entanto, Altet (2001, p. 33) considera que "a análise de prática é, em formação profissional, uma distanciação do agir e um retorno reflexivo sobre os atos profissionais por uma pessoa em questionamento”. Assim, a análise de práticas consiste em se distanciar da ação e tentar avaliar os atos executados por meio de um "novo olhar" mais reflexivo, o qual auxilia o docente a refletir sobre sua prática, permitindo que este possa realizar mudanças em futuras práticas. Entretanto, esta análise prática não é simples ou fácil, uma vez que demanda tempo e escolha do dispositivo adequado para que seja realizada de forma sistematizada.

A análise da prática docente pode ocorrer por meio do estudo das sequências didáticas, as quais compreendem indiretamente três principais pilares: planejamento, intervenção e avaliação. Porém, há várias dimensões didáticas que envolvem diferentes sequências de atividades de ensino-aprendizagem, abrangendo a organização dos conteúdos, as características e o uso de materiais didáticos distintos, variados vínculos entre professores e discentes, assim como diversas organizações sociais, espaciais e temporais da aula. Devido a isto, há uma necessidade iminente de instrumentos e recursos mais definidos, para que se possa empreender efetivamente a análise da prática (ZABALA, 2020).

\section{Metodologia}

Trata-se de um trabalho qualitativo, descritivo, exploratório e analítico, que buscou uma maior aproximação entre o cotidiano da supervisora de estágio e as experiências vividas. $\mathrm{O}$ método de investigação utilizou técnicas de observação e análise documental, possibilitando recorrer aos conhecimentos, experiências e introspecções. 
O conteúdo das observações envolveu uma parte descritiva e outra mais reflexiva, conforme sugerido por Bogdan e Biklen (1982), baseada nos registros, documentos e dispositivos utilizados como ferramenta de trabalho pela supervisora.

Assim, o relato das rotinas de estágio curricular supervisionado (ECS) foi realizado pelo próprio pesquisador e obtido a partir de um caderno de registros, protocolos e programa do estágio e relatórios. As análises foram baseadas na rotina diária de uma supervisora de ECS em análises clínicas do curso de Biomedicina, no período de 2019 a 2020, em uma instituição privada do interior de São Paulo, nos períodos vespertino e noturno.

Neste trabalho, utilizei como dispositivo a reflexão crítica proposta por Smyth (1992), pois ela nos permite fazer uma análise crítica de nossas ações e práticas por meio de quatro ações que se desenvolveram na forma de um estudo descritivo, envolvendo como técnica o relato das rotinas desenvolvidas em situação de ECS.

Os elementos para a análise da prática foram encontrados na reflexão crítica das quatro ações propostas por Smyth (1992): Descrever (as ações do professor na sala de aula); Informar (os princípios que embasam suas ações); Confrontar (a fundamentação teórica do seu modo de ensinar); e Reconstruir (o repensar a sua prática).

As orientações sobre a análise de prática foram disseminadas na disciplina "O saber dos professores, a formação e o trabalho docente: elementos para uma epistemologia da prática profissional” - PPG-Educação, UNESP/Rio Claro, 2020.

\section{RESUlTAdOS: A ATIVIDADE DE ANÁLISE DE PRÁTICA}

A escolha da rotina de trabalho a ser analisada corresponde a uma prática diária baseada no contato direto para transmissão de saberes aos discentes, o que desenvolvo como supervisora de estágio acadêmico obrigatório em análises clínicas do curso de Biomedicina em uma instituição privada do interior de São Paulo

Ao final de cada dia, indiretamente, faço uma reflexão acerca do desenvolvimento do estágio naquele período executado, procurando identificar alguns pontos que não ocorreram conforme o planejado - assim como a aceitação discente referente à forma como foi abordado o tema, a fim de promover melhorias, objetivando maior compreensão e aprendizado discente.

O conceito de rotinização foi proposto por Giddens (1987), permitindo a associação entre os saberes, tempo e trabalho. Esse conceito abrange o ensino, colocando em evidência seu caráter rotineiro e a importância das rotinas, para compreender a vida na sala de aula e o trabalho do professor. As rotinas seriam meios de gerir a complexidade das situações de interação, bem 
como modelos simplificados da ação, uma vez que elas proporcionam a estruturação dos atos, baseada em uma maneira de agir estável, uniforme, repetitiva. Assim, o estudo de tais regularidades é fundamental para entender a natureza social e a evolução do trabalho docente, pois elas não se reduzem às formas exteriores ou a simples hábitos, mas estruturam o sentido que os atores dão às suas atividades e às relações sociais que elas desencadeiam (TARDIF, 2000).

\subsection{PRIMEIRA ETAPA - DESCREVER: A ROTINA DE TRABALHO}

\subsubsection{O ESTÁGIO CURRICULAR SUPERVISIONADO (ECS)}

O ECS faz parte da proposta pedagógica do curso de Biomedicina. Ele pode ter $800 \mathrm{~h}$, se o estudante optar pelo Programa em Análises Clínicas; ou 534 h, se envolver mais de uma habilitação, tendo como períodos de realização o $9^{\circ}$ e $10^{\circ}$ períodos (turnos matutino e noturno) do curso.

Os programas de estágios estão ancorados no plano de trabalho dos estágios, apresentados no regulamento interno dos ECS do curso de Biomedicina e no plano de trabalho do Programa de Estágio em Análises Clínicas. A instituição compromete-se a oferecer a todos os discentes, em seu próprio Laboratório de Análises Clínicas, o ECS na área de "Análises Clínicas”; enquanto estágio em "Outra habilitação", poderá ser realizado em laboratórios didáticos e de pesquisa da Instituição.

A avaliação dos ECS baseia-se no processo de aprendizagem dos aspectos práticos e teóricos, postura ética profissional e respeito demonstrado aos princípios e valores fundamentais da vida humana. Cada grupo de 05 a 08 discentes é acompanhado por um supervisor dentro dos diferentes setores de ECS em Análises Clínicas e avaliado por meio da Avaliação Diária (AD); Avaliação Teórica, Prática ou Oral (ATPO); Relatório Final (RF) e o SPA.

O ECS em Análises Clínicas objetiva promover o exercício prático e o aprimoramento dos conhecimentos técnico-científicos, com as seguintes finalidades: a) articulação da formação acadêmica com a prática profissional; b) desenvolvimento da interdisciplinaridade; c) aproximação da Universidade com a comunidade (extensão); d) compreensão das relações no trabalho; e) aperfeiçoamento e aquisição de técnicas de trabalho; f) promoção de um período de permanência orientada no exercício profissional. 
Nesta ação, auxílio/supervisiono os discentes durante a execução e interpretação dos exames que compõem a prática laboratorial: imunologia, hematologia, microbiologia, bioquímica, parasitologia, urinálise e lavagem/esterilização, a fim de habilitá-los em patologia clínica. Os setores de imunologia, bioquímica, urinálise e lavagem/esterilização são de minha incumbência, uma vez que trabalho com mais duas outras supervisoras, as quais dividem a responsabilidade pelos demais setores. Todas nós somos formadas na mesma instituição em que trabalhamos, mas com habilitações biomédicas diferentes e mestrados em áreas distintas.

Também trabalho com outras duas biomédicas (responsável técnica - RT e corresponsável técnica), cuja responsabilidade se restringe à rotina laboratorial dos pacientes (liberação de laudos/resultados), enquanto a supervisão se responsabiliza pela área acadêmica (discentes/ensino). Embora haja uma divisão de trabalhos, trabalhamos na forma de "laboratório-escola", ofertando exames a baixo custo para a população, visando obter amostragens para o ensino-aprendizagem das técnicas em análises clínicas.

Assim, realizamos no cotidiano um trabalho de extensão universitária à comunidade da cidade e região, que busca diagnósticos laboratoriais com preço justo, promovendo um processo científico, educativo e cultural que articula o ensino e a pesquisa de forma indissociável, viabilizando a relação universidade-sociedade.

Concluindo, essas são as ações que realizamos na prática compartilhada por mim e minhas colegas de trabalho. Outras atividades também são atribuídas esporadicamente, em função de eventos institucionais, como, por exemplo, feira das profissões e ação itinerante. Dessa forma, ao descrever a minha rotina de trabalho, há apenas as ações diárias desempenhadas, as quais são basicamente executadas repetidamente pelos períodos vespertino e noturno, totalizando uma jornada de $8 \mathrm{~h} / \mathrm{dia}$.

\subsubsection{O COTIDIANO DE TRABALHO COM DISCENTES, FUNCIONÁRIOS E PACIENTES}

O ECS do curso de Biomedicina é supervisionado por uma equipe constituída pelo Coordenador do Curso de Biomedicina, Coordenadores do Estágio, Professores de Estágio e Supervisores. As supervisoras de estágio possuem como atribuições: acolher os acadêmicos no local de estágio; apresentar aos estagiários as normas de funcionamento do local concedente de estágio; elaborar e apresentar, juntamente com Professores de Estágio, os planos de atividades atualizados e específicos de cada setor de estágio; apresentar e acompanhar as atividades que deverão ser realizadas pelos estagiários; manter organizados os registros acadêmicos do sistema de avaliação e frequência. 
A vivência laboratorial, exercida durante as aulas práticas, é complementada pela realização do ECS em Análises Clínicas, com a aplicação de técnicas e recursos diversificados, visando o início da formação do investigador científico. Essa abordagem permite ao discente uma visão do exercício profissional, conferindo-lhe a experiência da relação biomédico/paciente em condições de supervisão, com abrangência preventiva, analítica e diagnóstica do binômio saúde/doença.

Perante isto, o principal objetivo durante o ECS é auxiliar os discentes ao longo da execução e interpretação dos testes clínicos, para que eles compreendam o princípio, a finalidade e a aplicação clínica de cada um dos testes, assim como o tipo de material biológico empregado em cada um dos exames.

Para isto, eu dividi o ECS em três momentos: compreensão da técnica que será executada, por meio da leitura do POP (procedimento operacional padrão) e confecção de uma ficha resumo do mesmo; execução da técnica supervisionada, seguindo as orientações do POP; análise dos resultados e interpretação clínica baseada nos valores de referência, juntamente com a pesquisa sobre os achados clínicos. Parte da avaliação diária é realizada por meio da entrega/correção da ficha resumo, análise da execução prática e interpretação clínica, compondo uma única nota final.

Esta espécie de "metodologia" foi aplicada nos quatro setores pelos quais sou responsável, variando apenas o exame realizado. Além disso, também realizei o trabalho "acadêmico interno", composto pela confecção da análise de desempenho diário de cada discente, controle de frequência e preparo de avaliações práticas. Entretanto, algumas atividades variam em conformidade com as demandas diárias e, portanto, não podem ser anteriormente previstas - consequentemente, é difícil fazer um planejamento diário.

\subsection{SEGUNDA ETAPA - INFORMAR}

Apesar de a minha rotina diária variar com a demanda, busco sempre ter um planejamento geral, o qual é composto por todas as atividades que devo desenvolver com cada discente em todos os setores sob minha responsabilidade. Sendo assim, busco desenvolver todo o conteúdo com cada discente, individualmente, a fim de que todos tenham as mesmas oportunidades de aprendizado.

As diretrizes curriculares nacionais (DCNs) sugerem a necessidade de formação de profissionais de saúde humanistas, generalistas, críticos e reflexivos. Nessa linha de orientação, considero que a organização do estágio nas três partes descritas acima possibilita ao discente 
desenvolver o conhecimento de formas diversas por meio da leitura, reprodução auxiliada e pesquisa. Assim, possibilito a construção do saber por meio de ligações com diversos conteúdos estudados em outras disciplinas (transversalidade) e uma metodologia ativa de aprendizagem, a fim de desenvolverem competências reflexivas e críticas.

Para isto, diariamente me adapto às mudanças e busco desenvolver melhorias em cada setor, a fim de proporcionar o melhor preparo do discente para o mercado de trabalho, pois tenho como desafio romper o modelo de formação fragmentado e tecnicista, objetivando formar profissionais de saúde mais humanistas, com condições de trabalhar em equipe, de forma integrada e com foco na integralidade da atenção à saúde.

Durante minha rotina prática, também é possível identificar algumas influências de referenciais teóricos da educação, como Vygotsky (1984) e Freire (1996). A abordagem socioconstrutivista, descrita por Vygotsky (1984), baseada na existência de troca (relação) no processo de aprendizagem, pode ser observada na vivência laboratorial do campo de estágio da Biomedicina, onde ocorre a troca de experiências, e até mesmo saberes, entre professor-aluno e aluno-aluno. Há também traços de uma educação problematizadora, proposta por Freire (1996), durante a discussão de estudos de casos norteados pelo diálogo entre educandos e educador ou até mesmo na abordagem técnica investigativa pela busca do conhecimento acerca de seu princípio e finalidade.

\subsection{TERCEIRA ETAPA - CONFRONTAR}

A perspectiva bakhtiniana (BAKHTIN, 1970) sugere que o processo ensinoaprendizagem pode ser contextualizado como um fenômeno social e ideologicamente constituído, exemplificado como uma arena de conflitos de vozes e valores mutáveis e concorrentes. Tal perspectiva se aplica diretamente na supervisão, ao se considerar o campo de estágio uma "arena de conflito de vozes" dos discentes (futuros profissionais) com os profissionais e entre os próprios profissionais, além de "valores mutáveis e concorrentes" devido às mudanças que ocorrem no próprio campo da saúde, promovidas pelos avanços tecnológicos e pesquisas.

Dessa forma, nota-se a necessidade inerente de um profissional menos técnico e mais reflexivo, pois a reflexividade envolve: o conhecimento na ação (saber fazer); a reflexão na ação (adaptação do seu agir à complexidade da situação); a reflexão sobre a ação (processo que fomenta a evolução do professor) (SCHÖN, 1983). O que, para Tardif e Moscoso (2018), deveria envolver também a reflexão coletiva. 
Concluindo, a prática profissional é um processo de busca constante, composto pela reflexão diária de cada ação, diálogo e proposta. Tardif (2000) sugere que o saber possui diversidade e temporalidade, e evolui com a experiência de trabalho, estabelecendo uma correlação entre a formação dos professores e saberes. Isso implica diretamente na rotina de trabalho, pois, ao mesmo tempo em que elaboro práticas, estas são reelaboradas numa busca constante de aprender, reaprender, construir, reconstruir, pensar e repensar em todas as ações desenvolvidas. A ação prática não fica aprisionada em fórmulas prontas de ensinar (metodologias fechadas).

$\mathrm{Na}$ área da saúde não há "regras absolutas", mas, pelo contrário, existem muitas “exceções às regras”, exigindo dos profissionais mais reflexão e articulações entre os diversos conhecimentos, competências e saberes, em comparação à técnica propriamente dita.

Em geral, as escolhas das práticas são influenciadas pelos saberes adquiridos das vivências enquanto aluna, provenientes de todo o processo de formação. Minha prática docente retoma algumas experiências adquiridas durante o estágio na docência, realizado na disciplina de Biologia Celular do curso de Ecologia na UNESP/Rio Claro, e com o passar dos anos trabalhando como supervisora de estágio acadêmico.

Indiretamente, também acredito que tais práticas advêm do estilo de estudo realizado desde o ensino fundamental, assim como da influência de alguns traços de dispositivos disciplinares em situações em que exigimos atenção durante as explicações e demonstrações técnicas, não permitindo distrações como, por exemplo, conversas paralelas e consulta de materiais diversos. Também é possível identificar na minha rotina prática os princípios da moralidade, ética profissional e legislação laboratorial vigente, os quais foram ensinados durante minha graduação e pós-graduação.

O planejamento geral e a "metodologia" de três etapas também possuem as contribuições e influências explanadas acima. Esta "metodologia" se tornou uma forma de desenvolver um trabalho que me propiciasse um cotidiano menos agitado e com maior organização. De modo que se tornou um hábito que, em minha perspectiva, tem contribuído positivamente no desenvolvimento de meu trabalho.

\subsection{QUARTA ETAPA - RECONSTRUIR}

As mobilizações dos saberes contribuíram e influenciaram diretamente minha rotina prática. Entretanto, há outras atividades que constituem meu trabalho, nas quais identifico a necessidade inerente de realizá-las de maneiras diferentes. Essas mudanças podem gerar 
resistências e, devido a isto, estou refletindo, buscando a melhor forma de realizá-las, para que tragam ações positivas na supervisão de estágio.

Durante a execução da reflexão crítica proposta por Smyth (1992), pude identificar algumas dificuldades, dentre elas a mais relevante foi a diferença de aceitação discente entre os períodos vespertino e noturno perante a mesma atividade proposta. Isto me fez refletir acerca do motivo, proporcionando a especulação de alguns fatores, como, por exemplo: diferença de faixa etária (normalmente os discentes do período noturno costumam se enquadrar em uma faixa etária maior que a dos discentes do período matutino); horário e tempo disponíveis para execução da atividade (o período noturno possui 30 minutos a menos, comparado ao vespertino) e a possível influência de alguns fatores externos (a maioria dos alunos do período noturno trabalham e, ao iniciarem o estágio, encontram-se cansados e, consequentemente, com foco diminuído).

Além disso, também notei, em alguns alunos de ambos os períodos, a ausência de conhecimentos básicos para compreensão das técnicas executadas, assim como dificuldades de ação perante situações emergenciais, como, por exemplo, acidentes laboratoriais, e até mesmo dificuldades em buscar formas alternativas perante a ausência de um reagente ou acesso venoso.

A fim de reconstruir minhas práticas, objetivando melhorias, busquei soluções para que a aceitação discente do período noturno aumentasse. Dentre as possibilidades, pensei em propor a atividade em um formato mais dinâmico e comunicativo, devido ao tempo diminuído e ao elevado grau de distração proveniente da exaustão dos alunos. Já para as dificuldades discentes no campo de estágio, a proposta resolutiva seria uma capacitação discente no início do estágio ou até mesmo uma mudança na estrutura curricular, fornecendo alguns módulos de estágio anualmente dentro dos laboratórios institucionais, antes de o discente ingressar no estágio fornecido no Laboratório de Análises Clínicas.

Entretanto, este processo é moroso, mas acredito que o processo de reflexão irá contribuir efetivamente na identificação de outras práticas que necessitam ser melhoradas, de modo a repensar a fim de ressignificá-las e, consequentemente, melhorar a minha prática profissional.

\section{DisCUSSÃo DOS DADOS: ANÁLISE DA PRÁTICA NO CAMPO DA BIOMEDICINA}

Durante as atividades cotidianas do ECS, ocorreu a apropriação, produção e mobilização de diversos saberes, ao organizar as situações de ensino e aprendizagem (SOUZA NETO; BORGES, 2016). Assim, o dinamismo do estágio exige mobilização constante dos saberes 
experienciais, a fim de conciliar o tempo com as situações cotidianas do estágio. Porém, esta interação é complexa, variada, comportando tensões e dilemas importantes, uma vez que o objeto de trabalho, os discentes, apresentam algumas características, como individualismo e heterogeneidade, que interferem no desenvolvimento do estágio.

O binômio saúde e educação é considerado como interfaces indissociáveis que se articulam entre si, uma vez que caminham juntas na realidade das práticas sociais. Nesta perspectiva de educação em saúde, os profissionais de saúde atuam como colaboradores, atores e responsáveis pelo desenvolvimento da prática educativa (FERNANDES; BACKES, 2010).

De acordo com Schön (1995), o professor deve esforçar-se para compreender o processo de conhecimento do discente e, para isto, o docente articula o seu conhecimento da ação com o saber do campo de atuação (local de atuação). Ou seja, o professor exerce a capacidade de individualizar, fornecendo atenção ao discente, para observar o seu grau de compreensão e dificuldades.

Corroborando o descrito acima, Tardif (2000) relata que o componente individual impede a formulação de uma solução geral para os problemas cotidianos, transformando-se num obstáculo a toda generalização, às receitas e às técnicas ditas como definitivas. Para o mesmo autor, ensinar é fazer escolhas, elaborar estratégias em plena interação com os discentes. Estas escolhas e estratégias variam de acordo com os conhecimentos, as experiências, as convicções dos professores e, evidentemente, dos próprios discentes.

Segundo Pimenta e Lima (2010), os saberes se constituem ao longo do processo de formação pela aquisição de conhecimentos teóricos baseados na tríade: saberes das áreas específicas, saberes pedagógicos e saberes da experiência, corroborando a realidade vivida no estágio. Neste contexto, a formação no ensino superior exige uma intrínseca relação entre as práticas pedagógicas e as transformações sociais, para que ocorra a formação de um profissional qualificado que atenda às demandas contemporâneas.

Em geral, há a ausência de reconhecimento da prática pedagógica como fio condutor para o ensino, podendo ser atrelada à história da formação do profissional na área da saúde, cuja base é dada por um modelo de educação centrado no professor, em que a metodologia consiste numa estruturação curricular formada por disciplinas, fragmentando o conhecimento (SILVA, 2014). Esta fragmentação e a especialização do conhecimento, comumente encontrada nos cursos da área da saúde, são resultantes do processo de construção de hegemonia pautada no modelo biomédico (CONDÉ; D’AVILLA, 2020). 
Nesse enquadramento, é possível identificar a influência de práticas educativas tradicionais herdadas do paradigma biologista durante os séculos XIX e XX, ou seja, frequentemente os cursos de formação na área de saúde são baseados nas disciplinas de Biologia e Anatomia, que ocupam as primeiras ofertas nos currículos, deixando a posteriori aquelas que enfatizam a subjetividade e o contexto social. Assim, o modelo de formação dos profissionais de saúde priorizava o estudo do corpo humano e seus componentes, por meio das ciências básicas (SILVA, 2014).

O saber da Biomedicina está baseado nas interações entre os diversos saberes descritos por Tardif (2000), os quais orientam a ação dos biomédicos docentes e atende aos requisitos da essência do ser humano. O conhecimento é baseado de forma sistemática e dicotomizada entre a teoria e a prática, fazendo com que a atuação docente siga o modelo da racionalidade técnica, como descrito por Gonçalves e Gonçalves (2011).

Assim, noto que os saberes profissionais e os saberes pedagógicos articulam-se, no dia a dia, por intermédio da mediação entre nós, supervisoras, e os discentes. Durante a organização das atividades de ensino e de aprendizagem, acontece a relação teoria-prática, fundamentando a apropriação dos conhecimentos técnicos e da função político-social da atividade profissional a ser desempenhada. Consequentemente, a responsabilidade da supervisão corresponde a proporcionar a aproximação do discente com a realidade concreta, a fim de teorizar sobre ela, atuando no cotidiano da saúde.

Entretanto, encontro um grande desafio na área do estágio, enquanto supervisora, com a inclusão da integralidade e da humanização das práticas, para romper com os limites da formação fragmentada, a fim de reconstruir relações com outras áreas de conhecimento. Além disso, os profissionais da área de saúde incluem a reflexão crítica, na maioria das vezes, apenas nas experiências negativas, excluindo a aplicação desta durante as práticas concretas de ensino. Perante isto, proponho uma análise reflexiva diária acerca das práticas realizadas com os discentes, objetivando o aprimoramento delas e possibilitando até mesmo o desenvolvimento de novas.

\section{CONSIDERAÇõES FINAIS}

Com os objetivos de identificar e analisar os saberes mobilizados na prática de uma supervisora de estágio obrigatório do curso de Biomedicina, realizou-se este trabalho pautado nas quatro ações da reflexão crítica, tendo como "achados" uma pluralidade de saberes mobilizados: experiencial, curricular e disciplinar. 
A cartografia dos procedimentos utilizados no campo de estágio da Biomedicina mostrou que os saberes docentes não podem ser discutidos de forma isolada, devido à complexidade em que estes se inserem na constituição do processo ensino-aprendizagem. Porém, ficou evidente a necessidade de explorar mais os saberes pedagógicos, como forma de superar as dificuldades de acompanhamento do discente no campo de estágio.

Em relação ao exercício de análise das práticas, verificou-se que a atividade reflexiva possibilita a identificação dos princípios que orientam a prática docente. A análise das práticas também proporcionou a verificação de alguns avanços, os quais revelaram a presença de dispositivos de formação, como o POP, para a sistematização da análise prática e dispositivos avaliativos denominada "ficha prontuário". Ambos os dispositivos promovem aos discentes ganhos positivos no desenvolvimento acadêmico.

Em geral, verificou-se que a formação dos profissionais de saúde extrapola a educação para o domínio técnico-científico da profissão e se estende pelos aspectos estruturantes de relações e práticas em todos os componentes de interesse ou relevância social.

Finaliza-se este estudo com duas perspectivas principais: a primeira, a formação do profissional docente é crucial para o sucesso do ECS - assim, é esperado que a presente reflexão estimule outras reflexões a respeito do tema e origine novas pesquisas; a segunda, este estudo contribuiu para a compreensão da concepção de estágio e me fez refletir por meio da análise de minha própria formação pessoal e profissional.

\section{REFERÊNCIAS}

ALTARUGIO, Maisa Helena; SOUZA NETO, Samuel. The teacher mentoring role and the reflexive teacher formation during supervised internships in the science education área. Acta scientiarum. Education (online), v. 21, p. 174-192, 2019.

ALTET, Marguerite. As competências do professor profissional: entre conhecimentos, esquemas de ação e adaptação, saber analisar. In: PERRENOUD, Philippe. Formando professores profissionais: quais estratégias? Quais competências? Porto Alegre: Artmed, 2001. p. 23-35.

BAKHTIN, Mikhail; VOLOCHINOV, Valentin Nikolaevich. Marxismo e filosofia da linguagem. São Paulo: Hucitec, 2006.

BOGDAN, Robert; BIKLEN, Sari Knopp. Qualitative research for education: an introduction to theory and methods. Boston: Allyn and Bacon, 1982. Disponível em: https://www.scirp.org/(S(i43dyn45teexjx455qlt3d2q))/reference/ReferencesPapers.aspx?Refer enceID $=537509$. Acesso em: 23 set. 2020. 
CONDÉ, Gruppo Ruella; D’AVILLA, Leher Elizabeth Menezes. Formação crítica de professores da área da saúde: uma experiência de cooperação entre Brasil e Uruguai. 2020.

CYRINO, Marina; SOUZA NETO, Samuel. O estágio curricular supervisionado na experiência brasileira e internacional. Revista Educação em Questão (online), v. 48, p. 86115, 2014.

FERNANDES, Maria Clara Porto; BACKES, Vânia Marli Schubert. Education in health: perspectives of the Family Health Strategy team under Paulo Freire's view. Revista Brasileira de Enfermagem, v. 63, n. 4, p. 567-573, 2010. DOI: 10.1590/s003471672010000400011. Disponível em: http://www.scielo.br/scielo.php?script=sci_arttext\&pid=S003471672010000400011\&lng=en\&nrm=iso\&tlng=pt. Acesso em: 23 set. 2020.

GATTI, Bernardete. Formação inicial de professores para a educação básica: pesquisas e políticas educacionais. Estudos em Avaliação Educacional, v. 25, n. 57, p. 24, 2014. DOI: 10.18222/eae255720142823.

GAUTHIER, Clermont. Por uma teoria da pedagogia: pesquisas contemporâneas sobre o saber docente. [S. 1.], 1998.

GIDDENS, Anthony. The Nation-State and Violence. The Australian and New Zealand Journal of Sociology, v. 23, n. 3, p. 433-442, 1987. DOI: 10.1177/1440783387 02300308. Disponível em: http://journals.sagepub.com/doi/10.1177/144078338702300308. Acesso em: 23 set. 2020.

GONÇALVES, Tadeu Oliver; GONÇALVES, Terezinha Valim Oliveira. Reflexões sobre uma prática docente situada: buscando novas perspectivas para a formação de professores. In: GERALDI, Corinta Maria Grisolia; FIORENTINI, Dario; PEREIRA, Elisabeth Monteiro de Aguiar. Cartografias do trabalho docente: professor(a)-pesquisador(a). Campinas: Mercado de Letras, 2011. p. 105-134.

HOLMES GROUP, Inc. East Lansing, MI. Tomorrow's Teachers: A Report of The Holmes Group, 1986.

NETO, Samuel Souza; CYRINO, Marina; BORGES, Cecilia. O Estágio Curricular Supervisionado como lócus central da Profissionalização do Ensino. Revista Portuguesa de Educação, v. 32, n. 1, p. 52-72, 2019.

ORTIZ, Heloísa Martins. O professor reflexivo: (re)construindo o "ser" professor. [S. 1.], 2003. p. 1-9.

PENTEADO, Regina Zanella; SOUZA NETO, Samuel. A Docência como Profissão: o Portfólio como Dispositivo e Política na Formação de Professores no Estágio Supervisionado em Educação Física. ARCHIVOS ANALÍTICOS DE POLÍTICAS EDUCATIVAS / EDUCATION POLICY ANALYSIS ARCHIVES, v. 29, p. 1-33, 2021

PÉREZ GÓMEZ, Angel. Formando professores como profissionais reflexivos. In: Os professores e sua formação, [S. 1.], v. 2, 1995. 
PIMENTA, Selma Garrido; LIMA, Maria Socorro Lucena. Estágio e docência: diferentes concepções. Poíesis Pedagógica, v. 3, n. 3-4, p. 5-24, 2010. DOI: 10.5216/rpp .v3i3e4.10542. Disponível em: https://www.revistas.ufg.br/poiesis/article/view/10542. Acesso em: 23 set. 2020.

RUFINO, Luiz Gustavo Bonatto; SOUZA NETO, Samuel de. A profissionalização do ensino no século XXI: desafios e possibilidades em tempos de crise. Humanidades \& Inovação, v. 1, p. 237-251, 2021.

SCHÖN, Donald A. The reflective practitioner. 1983. Disponível em:

https://www.sopper.dk/speciale/arkiv/book49.pdf. Acesso em: 26 set. 2020.

SCHÖN, Donald A. Knowing-In-Action: The New Scholarship Requires a New

Epistemology. Change: The Magazine of Higher Learning, v. 27, n. 6, p. 27-34, 1995.

DOI: 10.1080/00091383.1995.10544673. Disponível em:

https://www.tandfonline.com/doi/abs/10.1080/00091383.1995.10544673. Acesso em: 26 set. 2020.

SCHON, Donald A. Formar professores como profissionais reflexivos. [S. 1.], 1992. p. 77 91.

SHULMAN, Lee S. Those Who Understand: Knowledge Growth in Teaching. 1986. Disponível em:

http://depts.washington.edu/comgrnd/ccli/papers/shulman_ThoseWhoUnderstandKnowledge GrowthTeaching 1986-jy.pdf. Acesso em: 26 set. 2020.

SILVA, Silvana Rodrigues. Desvelando a atuação da/o enfermeira/o docente no estágio supervisionado em enfermagem: análise dos saberes docentes e práticas pedagógicas. 2014. Universidade Federal de Uberlândia - UFU, Uberlândia, MG, 2014.

SMYTH, John. Trabalho docente e política de reflexão. 1992. Disponível em: https://eric.ed.gov/?id=EJ449453. Acesso em: 26 set. 2020.

SOUZA NETO, Samuel; BORGES, Cecilia; AYOUB, Eliana. Formação de professores na contemporaneidade: desafios e possibilidades da parceria entre universidade e escola. PróPosições (Unicamp, online), v. 32, p. 1-10, 2021.

SOUZA NETO, Samuel; BORGES, Cecília. A profissionalização do ensino passados 30 anos: os desafios e as possibilidades de uma formação inicial na prática. In: III Congresso nacional de formação de professores; xiii congresso estadual paulista sobre formação de educadores - profissão professor: cenários, tensões e perspectivas. Anais... [S. 1.], n. May, p. 1490-1501, 2016. Disponível em:

http://www.unesp.br/anaiscongressoeducadores/ArtigoVisualizar?nome_arquivo=http://200.1 45.6.217/proceedings arquivos/ArtigosCongressoEducadores/6655.pdf. Acesso em: 26 set. 2020.

SOUZA NETO, Samuel; SARTI, Flavia Medeiros; CYRINO, Marina. O Grupo DOFPPEN: Docência, Formação de Professores e Práticas de Ensino. Formação Docente, v. 10, p. 49-66, 2018. 
TARDIF, Maurice; LESSARD, Claude. O trabalho docente. Elementos para uma teoria da docência como profissão de interações humanas. Journal of Chemical Information and Modeling, v. 53, n. 9, p. 1689-1699, 2011. DOI: 10.1017/CBO9781107415324.004.

TARDIF, Maurice. Saberes profissionais dos professores e conhecimentos universitários. Revista Brasileira de Educação, p. 5-24, 2000.

TREVISO, Patrícia; PINHEIRO DA COSTA, Bartira Ercília. Percepção de profissionais da área da saúde sobre a formação em sua atividade docente. Texto \& Contexto - Enfermagem, v. 26, n. 1, p. 5020015, 2017. DOI: 10.1590/0104-07072017005020015. Disponível em: http://dx.doi.org/10.1590/0104-07072017005020015. Acesso em: 26 set. 2020.

VYGOTSKY, Lev Semionovich. A formação social da mente. São Paulo: Martins Fontes, 1984.

ZABALA, Antoni. A prática educativa: como ensinar. Porto Alegre: Artmed, 1998. Disponível em: https://www.ifmg.edu.br/ribeiraodasneves/noticias/vem-ai-o-iii-ifmgdebate/zabala-a-pratica-educativa.pdf. Acesso em: 26 set. 2020. 